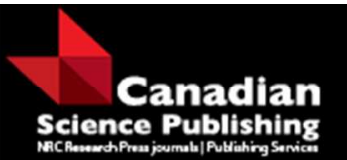

Canadian Journal of Forest Research

Revue canadienne de recherche forestière

\title{
Cost to produce carbon credits through fluctuating harvest levels in British Columbia, Canada.
}

\begin{tabular}{|r|l|}
\hline Journal: & Canadian Journal of Forest Research \\
\hline Manuscript ID & cjfr-2016-0132.R2 \\
\hline Danuscript Type: & Article \\
\hline Complete List of Authors: & $\begin{array}{l}\text { Man, Cosmin; University of British Columbia, Forest Resources } \\
\text { Management } \\
\text { Lyons, Kevin; University of British Columbia, Forest Resources } \\
\text { Management } \\
\text { Nelson, John D.; University of British Columbia } \\
\text { Bull, Gary; University of British Columbia }\end{array}$ \\
\hline Keyword: & $\begin{array}{l}\text { carbon price, harvest level, forest management, carbon credits, vegetation } \\
\text { simulator }\end{array}$ \\
\hline & \\
\hline
\end{tabular}

\section{SCHOLARONE ${ }^{\text {m }}$}

Manuscripts 
1 Cost to produce carbon credits through fluctuating harvest levels in British Columbia,

2 Canada.

3

4 Cosmin D. Man ${ }^{\text {a }}$ Kevin C. Lyons ${ }^{\mathrm{a}}$, John D. Nelson ${ }^{\mathrm{a}}$, and Gary Q. Bull ${ }^{\mathrm{a}}$

$5 \quad$ a Department of Forest Resources Management

6 Forest Sciences Centre

7 University of British Columbia

$8 \quad 2424$ Main Mall

9 Vancouver, BC

10 V6T 1Z4, Canada

11 E-mails:

12 Cosmin D. Man: cosmin.man@ubc.ca

13 Kevin C. Lyons: kevin.lyons@ubc.ca

14 John D. Nelson: john.nelson@ubc.ca

15 Gary Q. Bull: gary.bull@ubc.ca

16

17 Word Count (not including Abstract, References, Tables, and Figure captions): 5,068

18

19 Keywords: carbon price, harvest level, carbon storage, carbon sequestration, carbon credits, carbon offsets, forest management, management strategies, vegetation simulator. 


\section{Abstract}

The forest inventory of an actively managed forest estate in the Coast forest region of

27 British Columbia was used to investigate the potential of fluctuating harvest levels to produce

28 carbon credits. Fluctuating harvest levels allowed the target harvest level to fluctuate between the

29 baseline and a starting target harvest level (set at a lower level than the baseline) over the 25-year

30 life of the carbon project. Carbon credits continued to be produced for 4-15 years following the

31 harvest adjustment from the starting level to the baseline level. Carbon credits production for the

32 fluctuating harvest schedules was highest when the starting harvest level was held for 10-15

33 years and the baseline level for the remaining of the carbon project life. Carbon credit production

34 was sensitive to the initial age class structure of the forest estate, the harvest priority algorithm,

35 the starting target harvest level, and the timing of harvest adjustment from the starting level to

36 the baseline level. The cost to produce carbon credits using fluctuating harvest levels for the

37 studied forest estate varied between $\$ 32.2$ and $\$ 41.1 \mathrm{tCO}_{2} \mathrm{e}^{-1}$ (at $0 \%$ discount rate), which is 14 -

$38 \quad 17 \%$ lower than using a constant reduced harvest level. 


\section{Introduction}

The role of forest ecosystems to mitigate anthropogenic global climate change continues to be recognized at the international scale (Intergovernmental Panel on Climate Change 2014). It has been argued that forest management techniques can be used to increase the carbon storage in forest ecosystems (i.e., carbon sequestered from the atmosphere by the aboveground vegetation and stored in the forest ecosystem) (Cooper 1983; Smith et al. 1993; Parker et al. 2000) while continuing to meet the society's demand for timber, fiber, and energy (Kurz et al. 2002). The additional carbon storage can be converted to carbon credits (i.e., one metric tonne (t) of $\mathrm{CO}_{2} \mathrm{e}^{1}$ stored in addition to the baseline level) and if these carbon credits are sold, they can generate additional revenues. Two general strategies to increase carbon storage include increasing the growth rate (e.g., fertilization, use of genetically improved planting stock) and reducing the harvest (e.g., harvest reduction to a fixed target level, increased minimum harvest ages, increased area in reserves). It has been shown that in temperate forests, the harvest reduction strategies have a significantly higher potential to increase carbon storage than the increased growth rate strategies (Seely et al. 2002; Harmon and Marks 2002; Man et al. 2013). Moreover, out of the harvest reduction strategies mentioned above, the harvest reduction to a fixed target level is better able to adapt to changing markets and natural disturbances (Man et al. 2013). However, the opportunity cost due to harvest reduction (i.e., the cost of leaving the forest standing to produce carbon credits as opposed to generate revenue from selling the timber) can account for $58-97 \%$ of the total cost to produce carbon credits (Man et al. 2015).

\footnotetext{
${ }^{1} 1 \mathrm{t}$ of $\mathrm{CO}_{2} \mathrm{e}$ (e-equivalent) indicates the global warming potential of $1 \mathrm{t}$ of various greenhouse gases relative to the Carbon Dioxide as defined in the Assessment Report 5 of the Intergovernmental Panel on Climate Change (2014). In a forest ecosystem, the carbon storage is estimated in $\mathrm{t}$ of carbon and then converted to $\mathrm{t}$ of $\mathrm{CO}_{2} \mathrm{e}\left(1 \mathrm{t}\right.$ of carbon is $\left.3.667 \mathrm{tCO}_{2} \mathrm{e}\right)$.
} 
In this study, we continue the analysis conducted by Man et al. (2013) and Man et al.

69 (2015) on the potential of the harvest reduction strategies to produce carbon credits in British

70 Columbia. Man et al. (2013) explored the potential of alternate forest management strategies to

71 sequester and store carbon in two actively managed forest estates in British Columbia. Man et al.

72 (2013) found strategies that reduce harvest levels significantly outperformed strategies that

73 increase stand growth. Man et al. (2015) estimated the costs to produce carbon credits using

74 strategies that reduce harvest levels over the first 25-year period for three significantly different

75 and actively managed forest estates in British Columbia. The inclusion of the opportunity cost

76 due to harvest reduction significantly increased the cost to produce carbon credits (higher cost

77 for higher value stands).

78 The relatively high opportunity cost due to harvest reduction results in the question, can

79 harvest levels be fluctuated so that the opportunity cost is reduced while still producing carbon

80 credits? For this strategy to work, the production of carbon credits must have inertia. In this

81 context, inertia means once a forest estate is given a carbon credit production trajectory by

82 reducing the harvest below the baseline level, carbon credit production will continue after the

83 harvest is returned to the baseline level. The time length for which the carbon credit production

84 continues after the harvest is returned to the baseline level is defined as the inertia period. The

85 implementation of fluctuating harvest levels is a complex problem determined by the factors

86 affecting the carbon credit production rate (e.g., determining the starting target harvest level

87 (STHL) which gives the forest estate a carbon credit production trajectory) and by the factors

88 affecting the length of the inertia period (e.g., timing of the harvest return to the baseline level).

89 It is important to understand these factors and their interactions when fluctuating harvest levels

90 are implemented, particularly in the case of forest estates actively managed for profit where 
91 lowering the opportunity costs due to harvest reduction should decrease the cost to produce

92 carbon credits.

The objectives of this study are to determine if carbon credit inertia can be produced in an

94 actively managed forest estate, and to examine the effect of important variables on the length of

95 the inertia period, the number of carbon credits produced during the inertia period, and the cost

96 to produce carbon credits when fluctuating harvest levels are implemented.

97

98

99

100

101

102

103

104

105

106

107

108

109

110

111

112

113

\section{Methods}

Many of the methods used in this study are detailed in Man et al. (2013) and Man et al. (2015), yet for clarity and convenience critical information is included here.

\section{Study area and simulation models}

The Malcolm Knapp Research Forest (MKRF) was used to conduct the analysis. The MKRF is located approximately $60 \mathrm{~km}$ East of Vancouver within the Coast forest region of British Columbia. The timber supply analysis was conducted with a spatially explicit forest-level planning model (Forest Planning Studio (FPS-ATLAS) (Nelson 2003)), the carbon stock dynamics within the forest ecosystem were modelled with a spatial reference stand and landscape level model (the Carbon Budget Model for Canadian Forest Sector (CBM-CFS3)

(Kurz et al. 2009)), and the estimation of carbon credits produced followed the guidance of the Protocol for the Creation of Forest Carbon Offsets in British Columbia (British Columbia Ministry of Environment 2011). Detailed description of the MKRF, and assumptions used in FPS-ATLAS and CBM-CFS3 are found in Man et al. (2013), while detailed carbon credits accounting methodology is found in Man et al. (2015). 
Page 6 of 28

114

115

116

117

118

119

120

121

122

123

124

125

126

127

128

129

130

131

132

133

134

135

\section{Fluctuating harvest level scenarios}

In British Columbia, a carbon project (i.e., a course of action undertaken to achieve greenhouse gas reduction) is required to run for at least a minimum of 25 years (British

Columbia Ministry of Environment 2013). In a fluctuating harvest schedule, a starting target harvest level (STHL) is followed for a period of years and then, at some point before the end of the carbon project, the harvest level is increased to the baseline level. The baseline harvest level of the MKRF was determined to be $33000 \mathrm{~m}^{3}$ year $^{-1}$ (as the long term sustainable yield to be achieved for 100 years into the future). A minimum acceptable harvest level was determined to be $11000 \mathrm{~m}^{3}$ year $^{-1}$ (33\% of the baseline level) in order to achieve a minimum set of objectives (e.g., research, wildfire protection, and a minimum volume for the onsite sawmill). Starting with the baseline FPS-ATLAS database and keeping the same set of constraints (e.g., minimum harvest ages) as for the baseline scenario, three sets of five scenarios were simulated. Each of the three sets was defined by the STHL, which was set at $33 \%, 50 \%$, and $70 \%$ of the baseline level. For each of these three sets, five scenarios were simulated by holding the cut constant at STHL for $5,10,15,20$, and 25 years (the harvest reduction period) and then adjusting the harvest to the baseline level (Table 1). The simulations were run for 100 years in order to allow sufficient time to observe how carbon credit production is affected once the harvest has been adjusted from the STHL to the baseline level. In addition, to provide a reference in exploring the important variables affecting the inertia period, three harvest reduction scenarios were simulated where the annual harvest was held constant at 33\%, 50\%, and 70\% of the baseline level for the entire 100 year planning horizon. 
The total break-even carbon credit price $(P)$ was calculated using Eq. (1) derived by Man

137 et al. (2015) with its two components; $P_{H}$, the component of the total break-even carbon credit

138 price due to the opportunity cost of the reduced harvest (Eq. (2)) and $P_{C C}$, the component of the

139 total break-even carbon credit price due to the carbon project cost (Eq. (3)). Here, $P, P_{H}$, and $P_{C C}$

140 are assumed to be constant over the 25-year carbon project and $P$ is the sum of $P_{H}$ and $P_{C C}$. Eq.

141 (1) is identical to the levelization equation from Richards and Stokes (2004) and to the

142 discounted carbon equation from Boyland (2006).

$$
\begin{aligned}
P= & \frac{\sum_{t=0}^{n} \frac{\left(H_{B t}-H_{C t}\right) \cdot T N R+C C_{t}}{(1+r)^{t}}}{\sum_{t=0}^{n} \frac{C_{t}}{(1+r)^{t}}} \\
P_{H}= & \frac{\sum_{t=0}^{n} \frac{\left(H_{B t}-H_{C t}\right) \cdot T N R}{(1+r)^{t}}}{\sum_{t=0}^{n} \frac{C_{t}}{(1+r)^{t}}} \\
P_{C C}= & \frac{\sum_{t=0}^{n} \frac{C C_{t}}{(1+r)^{t}}}{\sum_{t=0}^{n} \frac{C_{t}}{(1+r)^{t}}}
\end{aligned}
$$

143 Here, $H$ is the harvested volume ( ${ }_{B}$ - baseline, ${ }_{C}$-carbon project), $T N R$ is the average timber net

144 revenue per cubic meter (the difference between the timber revenue and the harvesting cost,

145 estimated at $\$ 35 \mathrm{~m}^{-3}$ for the last 10 years of financial data for MKRF (Man et al. 2015)), $C$ is the 146 number of carbon credits produced for the 25 -year carbon project life, $C C$ is the carbon project 147 cost which includes the initial establishment and validation cost (estimated at $\$ 5.61 \mathrm{ha}^{-1}$ from 148 Galik et al. (2012)) and ongoing 5-year frequency verification cost (estimated at $\$ 1.52 \mathrm{ha}^{-1}$ from 
149 Galik et al. (2012)), $r$ is the discount rate (0-16\% real rates once inflation has been removed), $t$ is 150 the year of the planning horizon, and $n$ is the total number of years of the planning horizon (i.e., 151 the 25-year carbon project).

152 For each scenario, the annual change of carbon storage (i.e., carbon storage difference 153 between two consecutive years) was tracked for the entire 100-year planning horizon and four 154 metrics were quantified: 1) the length of time (in years) that the carbon credits continue to be 155 produced following the harvest adjustment from the STHL to the baseline level, this is termed 156 the carbon credits inertia period $(\mathrm{CCI}), 2)$ the number of carbon credits produced during $\mathrm{CCI}, 3)$ $157 C$, and 4) $P$.

\section{Results}

In the case of the baseline scenario, the annual change of carbon storage had an irregular

161 pattern, generally declining for the first 26 years of the 100-year planning horizon, then 162 increasing for the next 38 years (until year 64 of the 100-year planning horizon), and then 163 decreasing again for the remaining 36 years of the 100 -year planning horizon (Figure 1). The 164 irregular pattern is explained by the initial age class structure of the MKRF, where over $52 \%$ of 165 the timber harvest land base was older than 80 years (Man et al. 2013), and by the oldest-first 166 harvest priority algorithm used to simulate the harvest schedule. In the beginning of the planning 167 horizon, the harvesting of the oldest stands first reduced the carbon storage in the forest 168 ecosystem and consequently, the annual change of carbon storage declined. At the stand level, 169 when the tree cover was removed there was an immediate significant loss of carbon stored in the 170 dead organic matter pool (Figure 2) which caused the annual change of carbon storage for the 171 entire stand (i.e., total stand in Figure 2) to decline for the first year of the stand development. 
172 Following year 1 of the stand development (Figure 2), the growing biomass pool overcame the

173 initial loss of stored carbon and the annual change of carbon storage of the entire stand increased

174 to a peak value at year 57. At the forest estate level (Figure 1), as the area of older stands was

175 depleted by harvesting and the regenerated stands had higher yields than the stands they

176 replaced, the annual change of carbon storage increased gradually after year 26 and by year 64 of

177 the planning horizon it reached a higher value than the value at the beginning of the planning

178 horizon. Following year 64 of the planning horizon, the cycle repeated at a lower scale because

179 the forest was gradually transitioning to a younger age class structure where the oldest stands

180 were 120 years old (i.e., the highest minimum harvest age).

In the case of the harvest reduction scenario where the STHL was set to $33 \%$ of the

182 baseline for the entire 100-year planning horizon, the annual change of carbon storage was

183 irregular as well, generally increasing for the first 32 years and then decreasing for the remainder

184 of the 100-year planning horizon (Figure 1). Here, the carbon credit production occurred for the

185 entire 100-year planning horizon because the annual change of carbon storage for the harvest

186 reduction scenario (i.e., STHL set at $33 \%$ of the baseline for the entire 100 -year planning

187 horizon) was above the annual change of carbon storage of the baseline scenario. Note that the

188 carbon credit production was higher when the two patterns of annual change of carbon storage

189 (baseline and harvest reduction scenario) were more divergent. Similar patterns of the annual

190 change of carbon storage were observed for the harvest reduction scenarios where the STHL was

191 set to $50 \%$ and $70 \%$ of the baseline level for the entire 100 -year planning horizon.

192 In the case of the fluctuating harvest level scenarios where the STHL was set to $33 \%$,

$19350 \%$, and $70 \%$ of the baseline level, the annual change of carbon storage declined sharply at the

194 start of the CCI (i.e., when the harvest level was adjusted from the STHL to the baseline level) 
195 (Figure 1). The decline of the annual change of carbon storage for the fluctuating harvest level

196

197

198

199

200

201

202

203

204

205

206

207

208

209

210

211

212

213

214

215

216

217

scenarios continued for a number of years until it fell under the annual change of carbon storage

of the baseline scenario. At this point, the carbon credit production ceased and CCI ended. Note that as the timing of harvest level adjustment from the STHL to the baseline level (i.e., the harvest reduction period) approached year 25 of the 100-year planning horizon, the CCI extended past the 25-year carbon project life.

The CCI for the fluctuating harvest level scenarios was between 4 and 15 years and carbon credit production during CCI was between 8 and 103 thousand $\mathrm{tCO}_{2} \mathrm{e}$ (Figure 3 ). The STHL $(33 \%, 50 \%$, or $70 \%$ of the baseline level) did not affect the patterns of the CCI period or carbon credit production during the CCI period, but it had a visible effect on the scale of carbon credit production during the CCI period (which was highest when the STHL was set to 33\% of the baseline level). Regardless of the STHL, the CCI and carbon credit production during the CCI were at the highest levels when the harvest reduction period was between 10 and 15 years. Recall, the annual change of carbon storage for the baseline scenario was generally increasing after year 26 of the planning horizon and reduced the CCI for fluctuating harvest level scenarios with harvest reduction periods longer than 15 years (Figure 1). It was also observed that CCI was highly sensitive to the irregular patterns of the annual change of carbon storage for the baseline scenario. For example, between year 26 and 29, the annual change of carbon storage for the baseline scenario slightly increased and between year 29 and 35 it slightly decreased (Figure 1).

This subtle variation resulted in slightly lower CCI values for the 15 -year harvest reduction period compared to the 10- and 20-year harvest reduction periods when STHL was set at 33\% of the baseline level (Figure 3). Similarly, when STHL was set at 50\% of the baseline level, the CCI was lower for the 20-year harvest reduction period compared to the 15 - and 25 -year harvest 
218 reduction periods. Thus, CCI was highly sensitive not just to the STHL and the harvest reduction

219 period, but also to the interplay of the annual change of carbon storage between baseline and

220 fluctuating harvest level scenarios.

221 The CCI and the carbon credit production during the CCI were also sensitive to the initial 222 age class structure of the forest and the harvest priority algorithm. Recall, the initial age class 223 structure of the MKRF where over $52 \%$ of the timber harvest land base was older than 80 years 224 caused the annual change in carbon storage for the baseline scenario to decline for the first 26 225 years. Had the initial age class structure been younger, the annual change in carbon storage for 226 the baseline scenario would have had an increasing trend because the annual change of carbon 227 storage is higher in younger stands compared to older stands (Figure 2). The use of any other 228 harvest priority algorithm than oldest-first would have harvested more stands at younger ages in 229 the beginning of the planning horizon. Harvesting of younger stands in the beginning of the 230 planning horizon would have resulted in a lower decrease of the annual change in carbon storage 231 for the baseline scenario compared to the oldest-first harvest priority algorithm. Thus, the annual 232 change in carbon storage difference between the baseline and the fluctuating harvest level 233 scenarios would have been lower in a forest estate with a higher percentage of the area in 234 younger age classes than the MKRF or when using another harvest priority algorithm (i.e., not 235 oldest first). Consequently, the CCI and carbon credit production during CCI would have been 236 lower.

The number of carbon credits produced for the first 25-year carbon project life $(C)$ by the 238 range of fluctuating harvest level scenarios analyzed here was $8 \%$ to $88 \%$ of the maximum 239 (Table 2). In Table 2, for the fluctuating harvest level scenarios where the annual change of 240 carbon storage fell under the baseline (Figure 1), $C$ values accounted for the carbon credits loss 
Page 12 of 28

241 during the first 25 years of the 100-year planning horizon (e.g., 5- or 10-year harvest reduction

242 periods). The maximum $C$ was achieved when the STHL was set to $33 \%$ of the baseline level for

243 the entire 25-year carbon project life (i.e., the scenario identified as max in Table 2). The large

244 variation from the max was explained by the STHL, the harvest reduction period, and to a lesser

245 extent by the CCI and the carbon credit production during CCI. Higher $C$ values (over $67 \%$ of

246 max) were achieved when the STHL was at lower levels (e.g., 33\% or 50\% of the baseline level)

247 and the harvest reduction period was longer than 20 years. Recall, in order to maximize the

248 advantages of the CCI and the carbon credit production during CCI, the harvest reduction period

249 should be 10 to 15 years (Figure 3). Fluctuating harvest level scenarios with the STHL for 10 to

25015 years achieved $C$ values of $21 \%$ to $70 \%$ of the max. For example, $C$ values of approximately

$25150 \%$ of max could be achieved if STHL was set to 1) $33 \%$ of the baseline level for 10 years, 2)

$25250 \%$ for 15 years, or 3 ) $70 \%$ for 25 years (Table 2 ).

A second, third, or fourth 25-year carbon projects could be developed during year 26-50

254 of the 100-year planning horizon, year 51-75, or year 76-100, respectively. However, as noted in

255 Figure 1, the CCI looses momentum and carbon credits production stops before year 50 of the

256 100-year planning horizon. Only a constant harvest reduction level continued to produce carbon

257 credits past year 50, 75, or 100 . Therefore, once the previous 25 -year carbon project comes to an

258 end, a new strategy needs to be developed for the next 25-year carbon project.

The total break-even carbon credit price $(P)$ at $0 \%$ discount rate for the range of

260 fluctuating harvest level scenarios analyzed here varied between $\$ 32.2$ and $\$ 41.1 \mathrm{tCO}_{2} \mathrm{e}^{-1}$ (Table

261 2). The highest $P$ reduction from $\max (17 \%)$ occurred for the fluctuating harvest level scenario

262 where STHL was set to $50 \%$ of the baseline level for 10 years. Similar $P$ reductions from max

263 (14\% to $16 \%)$ occurred when the STHL was set to 1) $33 \%$ of the baseline level for 10 to 15 
264 years, 2) $50 \%$ for 15 years, or 3) $70 \%$ for 10 years. These results correlate well with the 265 advantages of the CCI and carbon credit production during CCI observed in Figure 3. A

266

267

268

269

270

271

272

273

274

275

276

277

278

279

280

281

282

283

284

285

286

somewhat surprising result was that $P$ could only be reduced by $17 \%$ from the max despite implementing the baseline harvest level for the last 15 years of the carbon project life. Man et al. (2015) found that $P$ was relatively independent of the target harvest level because of the high proportion of $P_{H}$ (over $96 \%$ in the case of the MKRF). In the case of the fluctuating harvest level scenarios with the highest $P$ reduction from max (17\%), the value of the opportunity cost was reduced from $\$ 19.010^{6}$ to $\$ 5.710^{6}$ (30\% of the max), but $P_{H}$ still represented a high proportion of $P\left(99 \%, \$ 31.8\right.$ out of $\left.\$ 32.2 \mathrm{tCO}_{2} \mathrm{e}^{-1}\right)$ (Table 2$)$. Thus, $P$ reduction through implementing fluctuating harvest levels was limited by the scale difference between the opportunity cost and the carbon project cost. In the case of the MKRF, the scale difference between $\$ 10^{6}$ for the opportunity cost and under $\$ 10^{4}$ for the carbon project costs was relatively large.

When the discount rate was increased from $0 \%$ to $4 \%-6 \%$, the $P$ reductions from max shown in Table 2 were reduced by half (Figure 4). The $P$ reductions from max became less than $2 \%$ when the discount rate was increased to more than $14 \%$. The effect the discount rate had on $P$ reductions from max is explained by Eq. (1). When the STHL was held constant over the 25year carbon project life, $P$ (as a constant value) needed to increase with an increasing discount rate. This was because the denominator of Eq. (1) (which includes the annual carbon credit production) was more sensitive to the discount rate increase than the numerator (which includes the annual total cost). When the harvest level fluctuated over the 25-year carbon project life, once the STHL was adjusted to the baseline level, the total costs were reduced to only the carbon project costs (i.e., the opportunity cost was zero) while the carbon credit production continued. Here, the numerator in Eq. (1) became less sensitive to the discount rate due to the sharp cost 
287 reduction. Thus, a higher discount rate resulted in higher increase of $P$ for the fluctuating harvest

288 level scenarios and consequently a smaller $P$ reduction from max.

The value of discount rate to be used in financial analyses is heavily debated in the

290 literature. Arguments for higher discount rates include the opportunity cost of investment funds

291 (i.e., the real rate of return on alternate investments), the time preference for earlier over later

292 consumption, diminishing marginal utility (i.e., discounting only products and services that are

293 known to be more abundant for future generations), and risk (Price 2014). The arguments for low

294 discount rates $(<1 \%)$ include intergenerational fairness (Stern 2007; Howarth 2009; Price 2014),

295 decision-makers' behaviour on capital markets (Howarth 2009), and supporting aggressive steps

296 to stabilize the anthropogenic global climate change (Cline 1992). Specific to forestry, higher

297 discount rates favour maintenance of current silvicultural systems and delays adopting new

298 regimes with the potential to yield higher timber volumes or improved ecosystem services (Price

299 2014). In the case of carbon projects on public land, relatively low discount rates may be

300 warranted for the following reasons; 1) generating public goods, 2) relatively a long term

301 horizons, 3), intergenerational fairness, 4) faster transition to regimes that favour ecosystem

302 services, and 5) help stabilizing the anthropogenic climate change.

When developing a carbon project, the fluctuating harvest levels can be used to take

304 advantage of the CCI and consequently produce carbon credits at lower prices. Carbon credit

305 prices in the range of $\$ 5$ to $\$ 16 \mathrm{tCO}_{2} \mathrm{e}^{-1}$ were reported for the improved forest management type

306 projects on the voluntary carbon markets (Peters-Stanley et al. 2013; Hamrick and Goldstein

307 2015) which are in line with the reduced timber harvesting abatement curves (McKinsey and

308 Company, 2009). In the case of the MKRF, the timber net revenue (TNR) was $\$ 35 \mathrm{~m}^{-3}$, and the $P$

309 reductions from max shown in Table 2 were not sufficient to produce carbon credits within the 
310

311

312

313

314

315

316

317

318

319

320

321

322

323

324

325

326

327

328

329

330

331

332

market price range. However, assuming a TNR of $\$ 15 \mathrm{~m}^{-3}$, a fluctuating harvest level scenarios with STHL set to $33 \%$ of the baseline for 10 years would have produced carbon credits at prices within the market price range whereas a constant reduced harvest level scenario (i.e., STHL set to $33 \%$ of the baseline for 25 years) would have not (Figure 5).

The TNR is sensitive not only to the timber market fluctuations, but also to the flexibility a forest manager has on the annual operational plans. In the case of the MKRF, the last 10-year financial data used to derive the TNR indicated a relatively constant timber revenue stream. The constant stream revenue is explained by the flexibility the forest manager had to adjust the harvest schedule to the timber market fluctuations. For example, favourable prices for cedar poles encouraged harvesting of 80-90 years old cedar stands. In the case of the forest estates with reduced operational flexibility, the TNR is expected to be more sensitive to the timber market fluctuations than the MKRF. Thus, the current carbon credit market range in Figure 5 could be more favourable in developing carbon projects for forest estates other than MKRF.

Some of the limitations of this study with potential large impacts on $P$ include simulation of stand-replacing natural disturbances and substitution benefits of carbon in harvested wood products. In the case of the MKRF, the impact of stand-replacing natural disturbances (if they occur) is relatively low because of its location (near Vancouver in the Coast forest region of British Columbia). In the case of other forest estates located in more remote and drier areas, the stand-replacing disturbances with shorter cycles than the Coast forest region reduce the LTSY, and consequently the carbon credit production. The substitution of greenhouse gas emissionsintensive products (e.g., steel, concrete, and plastic) with low emissions renewable harvested wood products is considered by many an essential carbon accounting tool to mitigate emissions from the forest sector (e.g., Lemprière et al. 2013). Because the baseline scenario has a higher 
333 level than any reduced harvest level scenarios, the substitution benefits are higher for the

334 baseline scenario. Consequently, the carbon credit production due to storage in manufactured

335 products is lower when substitution benefits are accounted. Thus, both limitations are expected

336 to increase $P$ because for the same TNR the carbon credit production is lower.

337 The financial benefits accrued from carbon credits present an opportunity for social

338 justice as they are distributed to improve the livelihoods of remote communities with positive

339 socio-economic impacts. For example, the Great Bear Rainforest carbon project was designed to

340 share the financial benefits between First Nations and the British Columbia Government

341 (Offsetters 2016)). However, a conservative approach to reduce harvesting for a relatively long

342 time may reduce the forest adaptability to climate change. The current relatively old stands were

343 regenerated by stand-replacing natural disturbances (e.g., wildfires) and they may not have the

344 capacity to adjust quickly enough to the forecasted changes in species habitat due to climate

345 change (Hamann and Wang 2006) and the forecasted carbon credit benefits may be reduced. Our

346 study presents an alternative to accrue carbon credit benefits while increasing the forest

347 adaptability to the forecasted changes in species habitat due to climate change. The fluctuating

348 harvest levels strategies described here give the forest estate a trajectory capable to deliver

349 financially-viable carbon projects and replace the less adaptable stands by increasing the harvest

350 level at a later time during the planning horizon.

351

352 Conclusions

The fluctuating harvest level strategies triggered a CCI of 4 to 15 years during which

354 carbon credit production was 8 to 103 thousand $\mathrm{tCO}_{2} \mathrm{e}$. The annual change of carbon storage

355 difference between the baseline and the fluctuating harvest level was the most important variable 
356 that affected the CCI and carbon credit production during the CCI. The annual change of carbon

357 storage difference between the baseline and the fluctuating harvest level was sensitive to the 358 initial age class structure of the forest estate, the harvest priority algorithm, the STHL, and the

359 timing of harvest level adjustment from the STHL to the baseline level (i.e., the harvest reduction 360 period). A lower STHL gave the carbon credit production a higher inertia which resulted in 361 longer CCI and higher carbon credit production during CCI. The highest levels of CCI and 362 carbon credit production during the CCI were achieved when the harvest reduction period was 363 between 10 and 15 years. achieve $21 \%$ to $70 \%$ of the maximum number of carbon credits produced for the 25 -year carbon project life. The maximum number of carbon credits was achieved when the STHL was set to $36733 \%$ of the baseline level for 25 years. The total break-even carbon credit prices $(P)$ at a $0 \%$ 368 discount rate were between $\$ 32.2$ and $\$ 41.1 \mathrm{tCO}_{2} \mathrm{e}^{-1}$ for the fluctuating harvest level scenarios. 369 The highest $P$ reductions from the maximum at a $0 \%$ discount rate (14\% to $17 \%)$ were achieved 370 when the STHL was held for 10 to 15 years, which correlated well with the results of the CCI 371 and carbon credit production during CCI. The $P$ reductions from the maximum were reduced by 372 half when the discount rate was increased from $0 \%$ to $4-6 \%$.

Another option to reduce the opportunity costs due to harvest reduction is to implement 374 carbon projects in forest estates with lower timber net revenues. This study compared $P$ between 375 fluctuating and constant reduced harvest level scenarios. It was found that implementation of 376 fluctuating harvest level scenarios where timber net revenue was set to $\$ 15 \mathrm{~m}^{-3}$ resulted in $P$ 377 below the carbon credits market range. For the same timber net revenue of $\$ 15 \mathrm{~m}^{-3}$, the constant 378 reduced harvest level scenarios resulted in $P$ above the carbon credits market range. The 
379 challenge of forest carbon projects proponents is to find forest estates with lower timber net 380 revenues where a carbon project can yield higher financial returns than the timber revenues.

381 However, this challenge is highly sensitive to forest condition (i.e., inventory and growth) and

382 financial markets fluctuations. Further research is needed to test the financial viability of carbon 383 projects in actively managed forest estates where timber net revenues are low relative to carbon 384 credit prices.

This study complements the analysis conducted by Man et al. (2013) and Man et al.

386 (2015) on the potential of the harvest reduction strategies to produce carbon credits in British

387 Columbia. In actively managed forest estates, strategies that reduce harvest levels are more

388 efficient at storing carbon in the forest ecosystem than strategies that increase stand growth (e.g.,

389 fertilization, use of genetically improved panting stocks) (Man et al. 2013). In the case of

390 strategies that reduce harvest levels, the inclusion of the opportunity cost due to harvest

391 reduction increases significantly the cost to produce carbon credits (Man et al. 2015). One

392 alternative to reduce the opportunity cost due to harvest reduction, and consequently reduce the

393 cost to produce carbon credits, is to utilize the inertia property of the carbon credit production by

394 implementing fluctuating harvest levels strategies. Lastly, the financial viability of strategies that

395 increase stand growth in actively managed forest estates needs to be addressed further. 


\section{REFERENCES}

Boyland, M. 2006. The economics of using forests to increase carbon storage. Can. J. For. 36, 2223-2234.

British Columbia Ministry of Environment. 2011. The Protocol for the Creation of Forest Carbon Offsets in British Columbia. www.env.gov.bc.ca/cas/mitigation/fcop.html (accessed 07 February 2013).

British Columbia Ministry of Environment. 2013. Information on Offsets Regulation. www.env.gov.bc.ca/cas/mitigation/ggrta/offsets_reg.html (accessed 07 February 2013)

Cline, W.R.1992. The Economics of Global Warming. Washington: Institute for International Economics.

Cooper, C.F. 1983. Carbon Storage in Managed Forests. Can. J. For. Res. 13, 155-166.

Galik, C.S., Cooley, D.M., Baker, J.S. 2012. Analysis of the production and transaction costs of forest carbon offset projects in the USA. J. Environ. Manage.112, 128-136.

Hamann, A., Wang, T. 2006. Potential effects of climate change on ecosystem and tree species distribution in British Columbia. Ecology 87, 2773-2786.

Hamrick, K., Goldstein, A. 2015. Ahead of the Curve. State of the voluntary carbon markets. Forest Trends. Url: www. http://foresttrends.org/releases/uploads/SOVCM2015_FullReport.pdf.

Harmon, M.E., Marks, B. 2002. Effects of silvicultural practices on Carbon stores in Douglas-fir-western hemlock forests in the Pacific Northwest, USA: results from a simulation model. Can. J. For. 32, 863-877. 
Howarth, R.B. 2009. Discounting, Uncertainty, and Climate Change. Economics for Equity and the Environment Network. At: www.e3network.org/briefs/Howarth_Discounting.pdf. Intergovernmental Panel on Climate Change. 2014. Climate Change 2014: Mitigation of Climate Change. Contribution of Working Group III to the Fifth Assessment Report of the Intergovernmental Panel on Climate Change [Edenhofer, O., R. Pichs-Madruga, Y. Sokona, E. Farahani, S. Kadner, K. Seyboth, A. Adler, I. Baum, S. Brunner, P. Eickemeier, B. Kriemann, J. Savolainen, S. Schlömer, C. von Stechow, T. Zwickel and J.C. Minx (eds.)]. Cambridge University Press, Cambridge, United Kingdom and New York, NY, USA.

Kurz, W.A., Dymond, C.C., White, T.M., Stinson, G., Shaw, C.H., Rampley, G.J., Smyth, C., Simpson, B.N., Neilson, E.T., Tyofymow, J.A., Metsaranta, J., Apps, M.J. 2009. CBM-CFS3: A model of carbon-dynamics in forestry and land-use change implementing IPCC standards. Ecol. Model. 220, 480-504.

Kurz, W., Apps, M., Banfield, E., Stinson, G. 2002. Forest Carbon accounting at the operational scale. For. Chron. 78, 672-679.

Lemprière, T.C., Kurz, W.A., Hogg, E.H., Schmoll, C., Rampley, G.J., Yemshanov, D., McKenney, D.W., Gilsenan, R., Bhatti, J.S., Beatch, A., and Krcmar, E. 2013. Canadian boreal forests and climate change mitigation. Environmental Reviews, 2013, 21(4): 293-321.

Man, C.D., Lyons, K.C., Nelson, J.D., and Bull, G.Q. 2013. Potential of alternate forest management practices to sequester and store Carbon in two forest estates in British Columbia, Canada. For. Ecol. Manage. 305, 239-247.

Man, C.D., Lyons, K.C., Nelson, J.D., and Bull, G.Q. 2015. Cost to produce Carbon credits by reducing the harvest level in British Columbia, Canada. Forest Policy Econ. 52, 9-17. 
McKinsey and Company, 2009. Pathways to a Low-Carbon Economy. Version 2 of the Global Greenhouse Gas Abatement Cost Curve. At www.mckinsey.com.

Nelson, J. 2003. Forest Planning Studio (FPS)-ATLAS Program: Reference Manual Version 6. Faculty of Forestry, University of British Columbia, Vancouver, BC, 104 pp. www.forestry.ubc.ca/atlassimfor/(accessed 07 February 2013).

Offsetters. 2016. Information on the Great Bear Forest Carbon Project. www.offsetters.ca/project-services/offset-projects/by-country/great-bear-forest-carbon-project (Accessed May 05, 2016).

Parker, W.C., Colombo, S.J., Cherry, M.L., Flannigan, M.D., Greifenhagen, S., McAlpine, R.S., Papadopol, C., Scarr, T. 2000. Third Millennium Forestry: What climate change might mean to forests and forest management in Ontario. For. Chron. 76, 445-463.

Peters-Stanley, M., Gonzalez, G., Yin, D. 2013. State of the Forest Carbon Markets 2013, Covering New Ground. Forest Trends. Url: http://www.foresttrends.org/documents/files/SOFCM-full-report.pdf.

Price, C. 2014. Temporal aspects in forest economics. In Handbook of Forest Resource Economics, Kant, S., and Alavalapati, J., editors. Routledge, New York.

Richards, K., Stokes, C. 2004. A review of forest carbon sequestration cost studies: A dozen years of research. Clim. Change 63, 1-48.

Smith, J.E., Heath, L.S., Skog, K.E., Birdsey, R.A. 2006. General Technical Report NE343 Methods for Calculating Forest Ecosystem and Harvested Carbon with Standard Estimates for Forest Types of the United States, USDA Forest Service. At www.fs.fed.us.

Stern, N. 2007. The economics of climate change: the Stern review. Cambridge and New York: Cambridge University Press. 
Table 1. Change of STHL to the baseline level for one set of five scenarios. Each of the three sets of five scenarios is defined by the STHL set at 33\%, 50\%, and $70 \%$ of the baseline level.

\begin{tabular}{lllllll}
\hline \multirow{2}{*}{$\begin{array}{l}\text { Scenario } \\
(1 \text { set of 5) }\end{array}$} & \multicolumn{6}{l}{ Harvest level between year: } \\
\cline { 2 - 6 } 1 & $1-5$ & $6-10$ & $11-15$ & $16-20$ & $21-25$ & $>25$ \\
\hline & & & & & & \\
2 & STHL & Baseline & Baseline & Baseline & Baseline & Baseline \\
3 & STHL & STHL & Baseline & Baseline & Baseline & Baseline \\
4 & STHL & STHL & STHL & Baseline & Baseline & Baseline \\
5 & STHL & STHL & STHL & STHL & Baseline & Baseline \\
\hline
\end{tabular}


Table 2. Number of carbon credits produced $(C)$, total break-even carbon credit price $(P)$, and opportunity cost $\left(P_{H}\right)$ for the first 25-year carbon project life at $0 \%$ discount rate and 5-year carbon project verification frequency

\begin{tabular}{|c|c|c|c|c|c|c|c|}
\hline \multirow{2}{*}{$\begin{array}{l}\text { Harvest } \\
\text { reduction } \\
\text { period } \\
\text { (years) }\end{array}$} & \multicolumn{2}{|l|}{$C$} & \multicolumn{2}{|l|}{$P$} & \multicolumn{3}{|c|}{ Opportunity cost } \\
\hline & $\mathrm{t} \mathrm{CO}_{2} \mathrm{e}$ & $\begin{array}{l}\% \text { of } \\
\max \end{array}$ & $\$ \mathrm{tCO}_{2} \mathrm{e}^{-1}$ & $\begin{array}{l}\% \% \\
\text { reduction } \\
\text { from } \max \end{array}$ & $\begin{array}{l}P_{H} \\
\left(\$ \mathrm{tCO}_{2} \mathrm{e}^{-1}\right)\end{array}$ & $\begin{array}{l}\text { Value } \\
\left(\$ 10^{6}\right)\end{array}$ & $\begin{array}{l}\text { Value } \\
\% \text { of } \\
\max \end{array}$ \\
\hline
\end{tabular}

STHL at $33 \%$ of the baseline level

$\begin{array}{rrrrrrrr}5 & 105523 & 21 \% & 35.6 & 8 \% & 34.9 & 3.7 & 19 \% \\ 10 & 228421 & 46 \% & 32.6 & 16 \% & 32.3 & 7.4 & 39 \% \\ 15 & 344061 & 70 \% & 33.0 & 15 \% & 32.8 & 11.3 & 59 \% \\ 20 & 433963 & 88 \% & 35.1 & 9 \% & 34.9 & 15.2 & 80 \% \\ 25 & 492 \mathbf{2 8 3} & \mathbf{1 0 0 \%} & \mathbf{3 8 . 7} & \mathbf{0 \%} & 38.6 & \mathbf{1 9 . 0} & \mathbf{1 0 0 \%}\end{array}$

STHL at $50 \%$ of the baseline level

$\begin{array}{lrrrrrrr}5 & 80798 & 16 \% & 35.6 & 8 \% & 34.7 & 2.8 & 15 \% \\ 10 & 180419 & 37 \% & 32.2 & 17 \% & 31.8 & 5.7 & 30 \% \\ 15 & 261154 & 53 \% & 32.5 & 16 \% & 32.3 & 8.4 & 44 \% \\ 20 & 331465 & 67 \% & 34.9 & 10 \% & 34.7 & 11.5 & 61 \% \\ 25 & 376255 & 76 \% & 38.0 & 2 \% & 37.8 & 14.2 & 75 \%\end{array}$

STHL at $70 \%$ of the baseline level

\begin{tabular}{lrrrrrrr}
5 & 38152 & $8 \%$ & 41.1 & $-6 \%$ & 39.3 & 1.5 & $8 \%$ \\
10 & 105061 & $21 \%$ & 33.4 & $14 \%$ & 32.8 & 3.4 & $18 \%$ \\
15 & 153072 & $31 \%$ & 34.3 & $11 \%$ & 33.9 & 5.2 & $27 \%$ \\
20 & 194768 & $40 \%$ & 35.3 & $9 \%$ & 34.9 & 6.8 & $36 \%$ \\
25 & 227039 & $46 \%$ & 38.5 & $1 \%$ & 38.2 & 8.7 & $46 \%$ \\
\hline
\end{tabular}



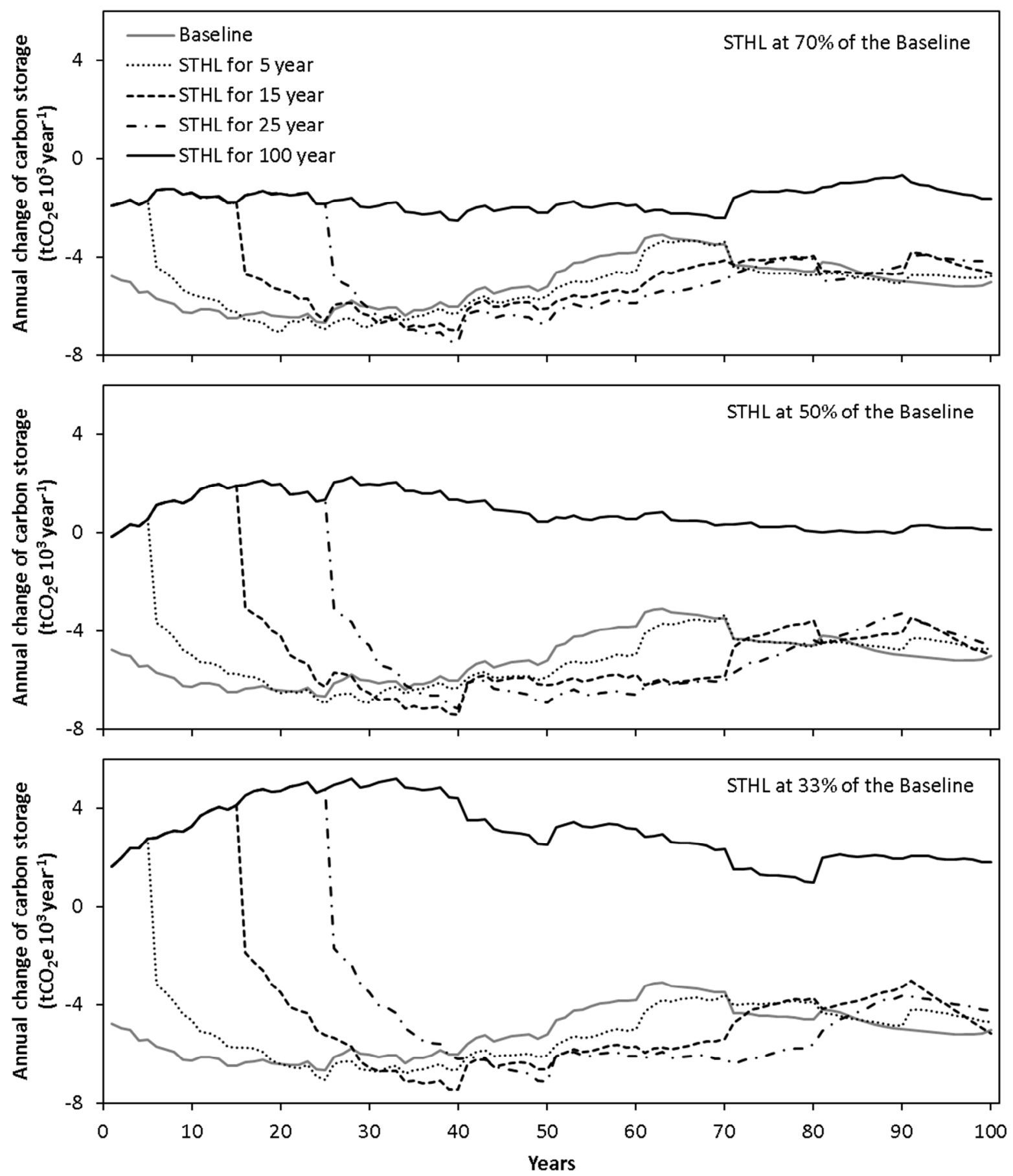

Figure 1. Comparing the annual change of carbon storage between the baseline scenario and the fluctuating harvest level scenarios: STHL is starting target harvest level. 
Page 25 of 28

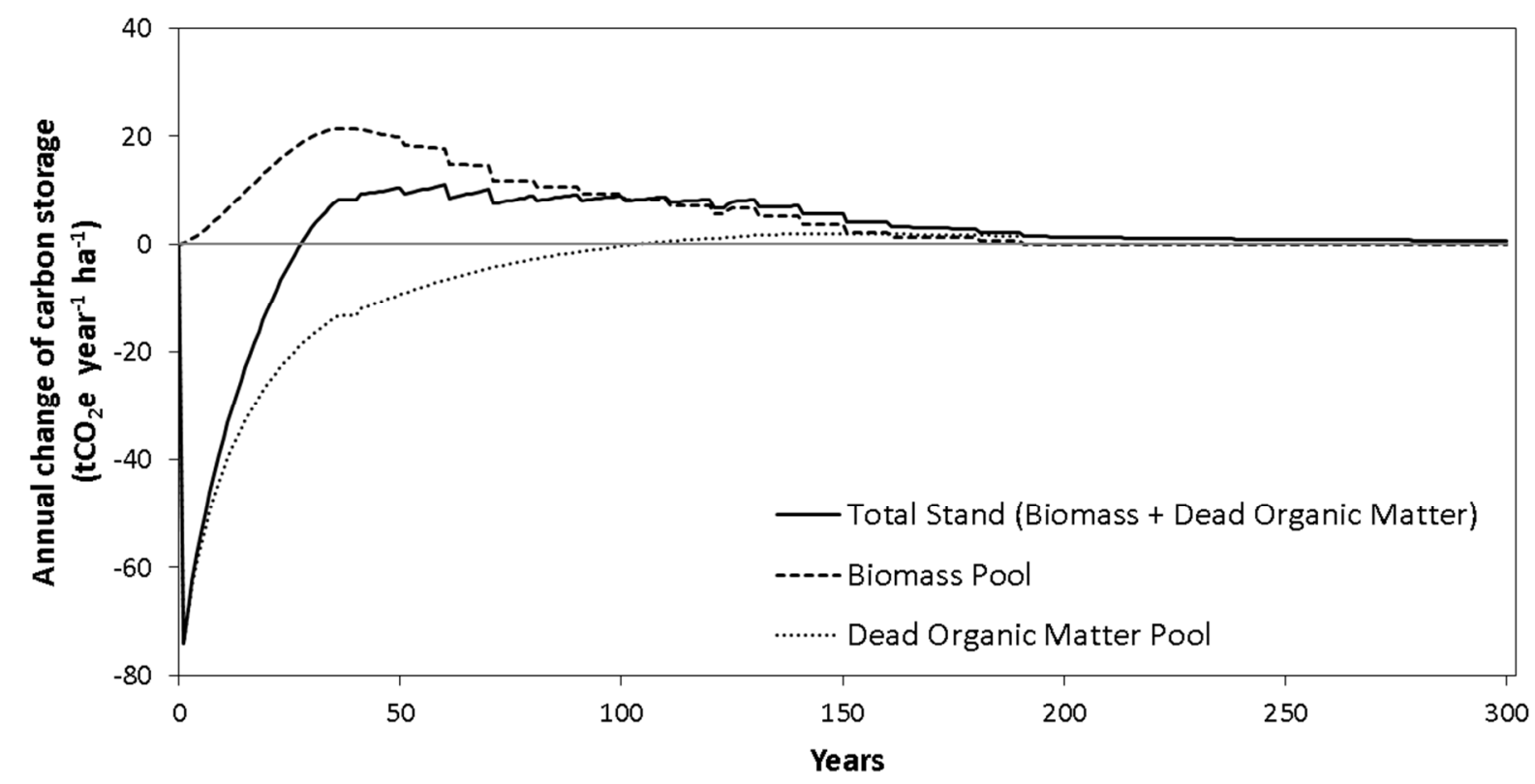

Figure 2. Annual change of carbon storage over time by ecosystem components in a typical stand at MKRF. The stand replacing disturbance in year 0 resulted in a significant loss of carbon storage in year 1 . 
Page 26 of 28
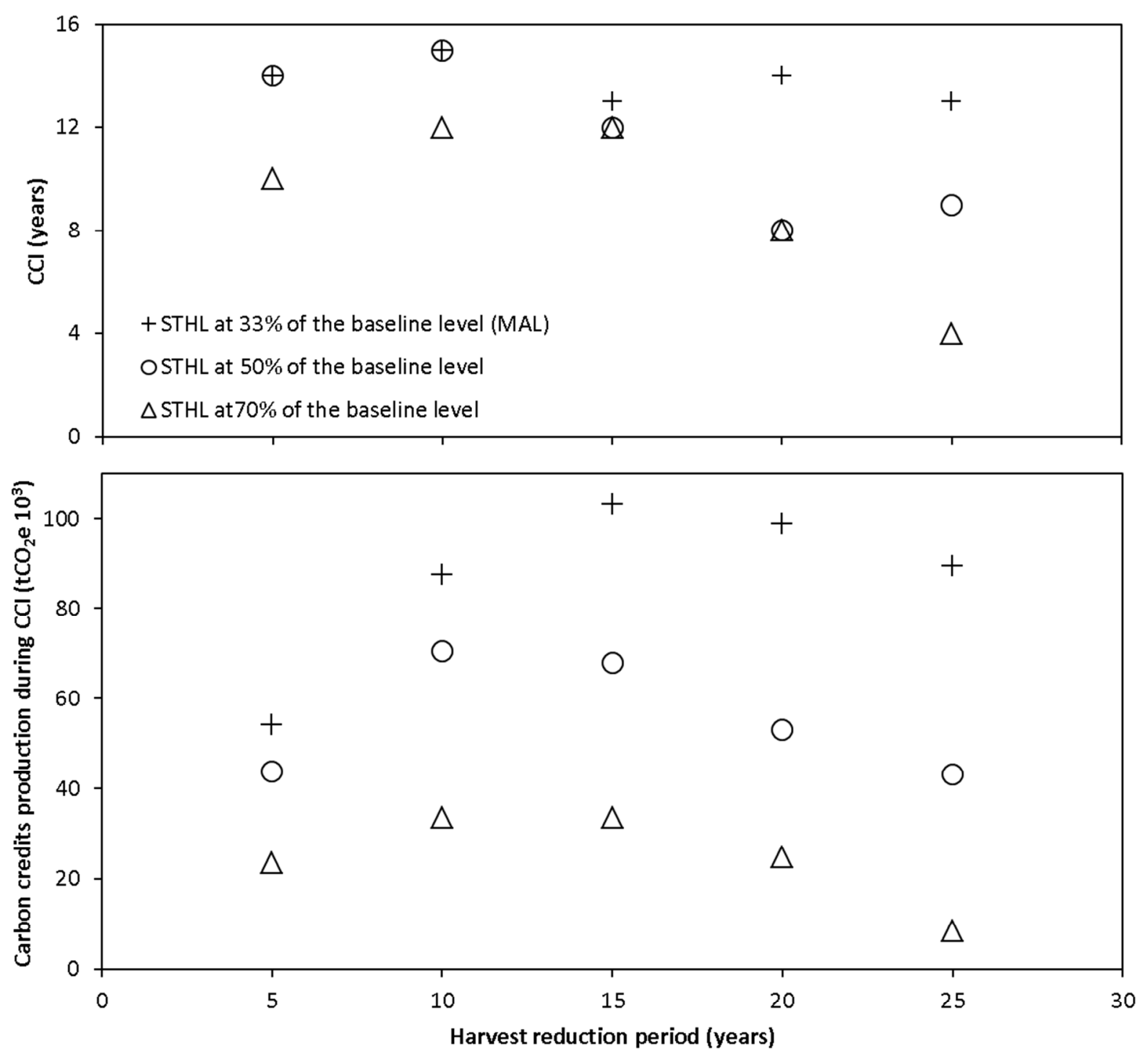

Figure 3. Comparing the carbon credit inertia periods (CCI) at MKRF when the starting target harvest level (STHL) is held constant for a range of harvest reduction periods 
Page 27 of 28

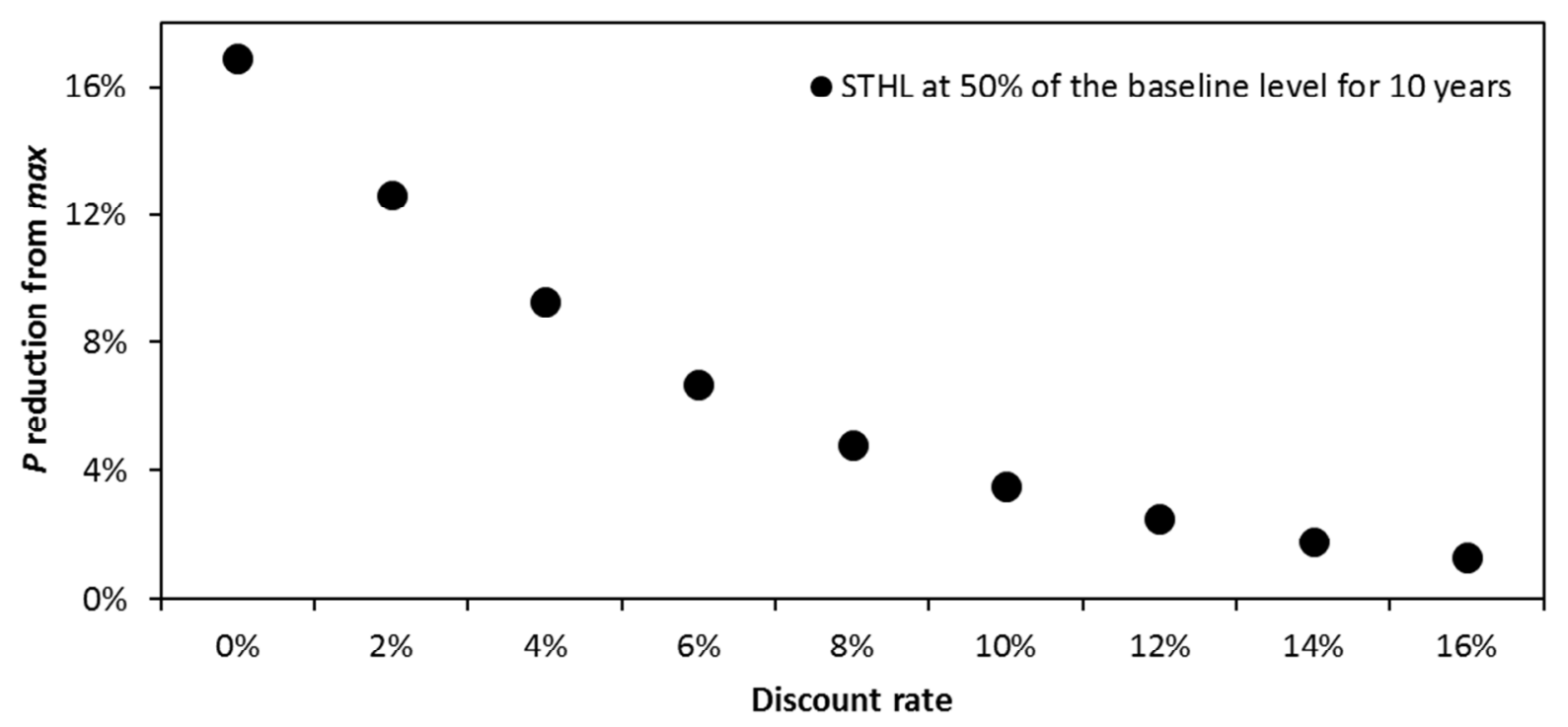

Figure 4. The effect of the discount rate on the total break-even carbon credit price $(P)$ reduction from max when STHL is set to $50 \%$ of the baseline level for 10 years (highest $P$ reduction from maximum): max value occurs when the starting target harvest level (STHL) is held constant over 25-year carbon project life. 


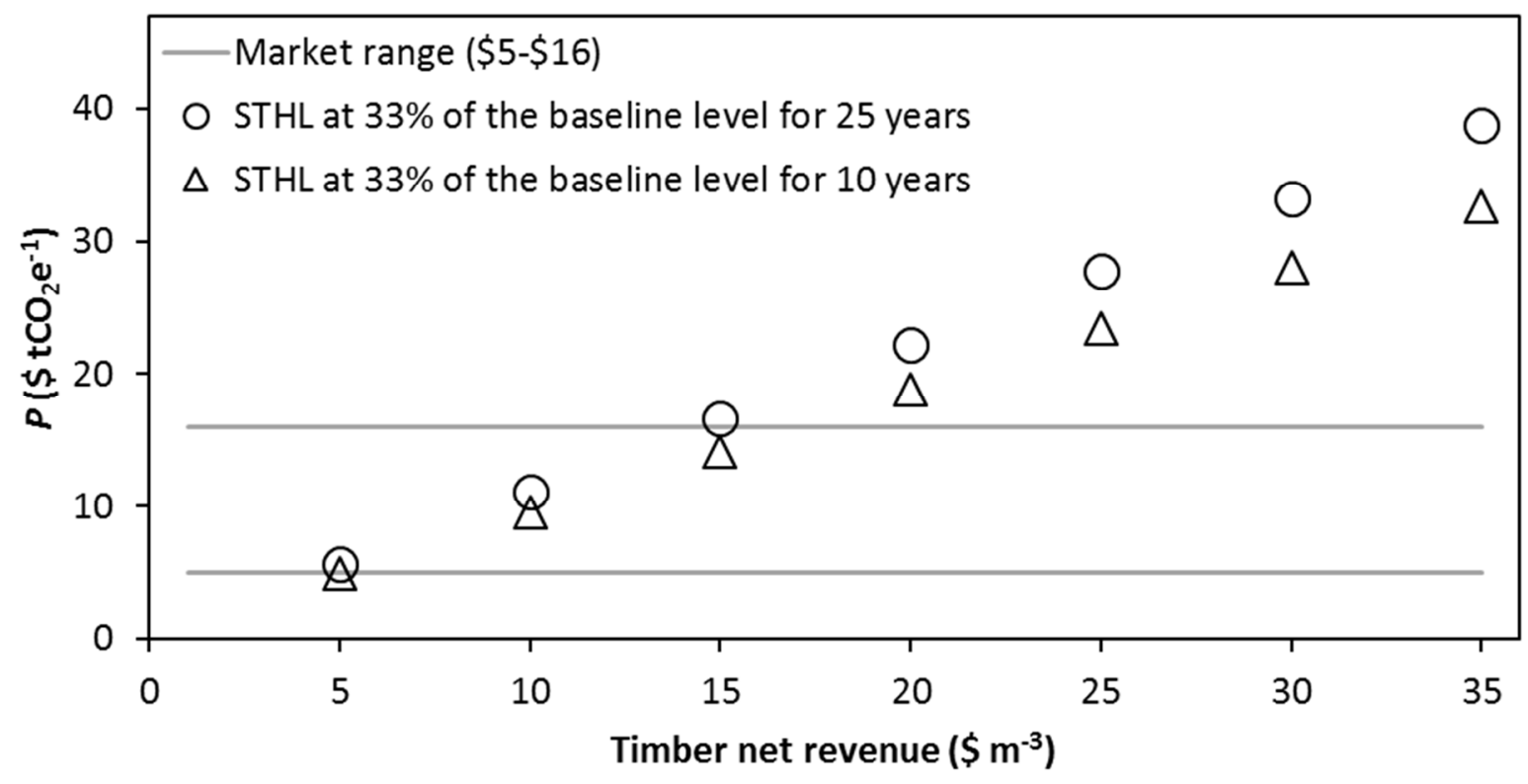

Figure 5. Comparing the carbon credit market price range to the total break-even carbon credit price $(P)(0 \%$ discount rate) for a range of timber net revenues (TNR) when the starting target harvest level (STHL) is set at 33\% of the baseline level for 10 years (fluctuating harvest level) and 25 years (constant reduced harvest level) 